\title{
Market integration and the persistence of electricity prices
}

\section{Working Papers 2016}

João Pedro Pereira | Vasco Pesquita |

Paulo M. M. Rodrigues | António Rua
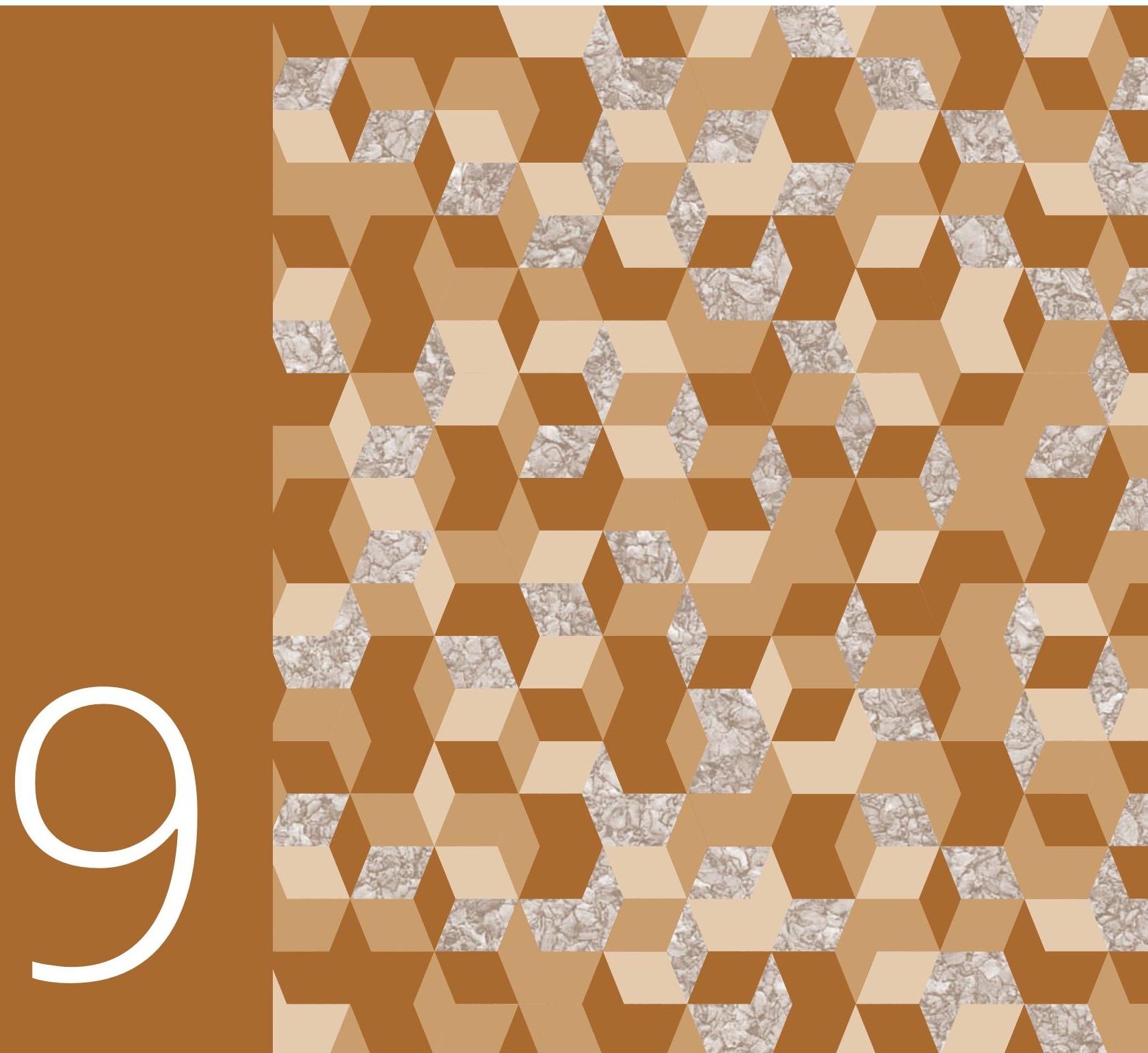



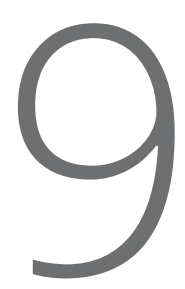

\section{Market integration and the persistence of electricity prices}

\section{Working Papers 2016}

João Pedro Pereira | Vasco Pesquita |

Paulo M. M. Rodrigues | António Rua

March 2016

The analyses, opinions and findings of these papers represent the views of the authors, they are not necessarily those of the Banco de Portugal or the Eurosystem

Please address correspondence to

Banco de Portugal, Economics and Research Department

Av. Almirante Reis 71, 1150-012 Lisboa, Portugal

T+351213130000 | estudos@bportugal.pt

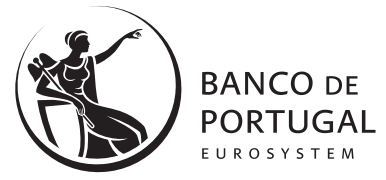

Lisbon, 2016 • www.bportugal.pt 
WORKING PAPERS | Lisbon 2016 • Banco de Portugal Av. Almirante Reis, 71 | 1150-012 Lisboa • www.bportugal.pt • Edition Economics and Research Department • ISBN 978-989-678-421-8 (online) • ISSN 2182-0422 (online) 


\title{
Market integration and the persistence of electricity prices
}

\author{
João Pedro Pereira \\ Nova School of Business and \\ Economics \\ Universidade Nova de Lisboa \\ Paulo M. M. Rodrigues \\ Banco de Portugal \\ NOVA School of Business and \\ Economics
}

\author{
Vasco Pesquita \\ Nova School of Business and \\ Economics \\ Universidade Nova de Lisboa \\ António Rua \\ Banco de Portugal \\ NOVA School of Business and \\ Economics
}

March 2016

\begin{abstract}
There is an ongoing trend of deregulation and integration of electricity markets in Europe and North America. This change in market structure has naturally affected the interaction between agents and has contributed to an increasing commoditization of electric power. This paper focuses on one specific market, the Iberian Electricity Market (MIBEL). In particular, we assess the persistence of electricity prices in the Iberian market and test whether it has changed over time. We consider each hour of the day separately, that is, we analyze 24 time-series of day-ahead hourly prices for Portugal and another 24 series for Spain. We find results consistent with the hypothesis that market integration leads to a decrease in the persistence of the price process. More precisely, the tests detect a break in the memory parameter of most price series around the year 2009, which coincides with a significant increase in the integration of Portuguese and Spanish markets. The results reinforce the view that market integration has an impact on the dynamics of electricity prices.
\end{abstract}

JEL: C50, E31, F36

Keywords: Electricity prices, market integration, persistence change, long memory.

Acknowledgements: We thank REN for providing data on Portuguese power generation. E-mail: joao.pereira@novasbe.pt; ; pmrodrigues@bportugal.pt; antonio.rua@bportugal.pt 


\section{Introduction}

A sound electricity market that meets demand and assures competitive prices is crucial to promote economic growth and sustain social welfare. Electricity is different from other commodities because it is not storable at a commercial large scale. The adjustment of demand and supply must be instantaneous, which causes the resulting market price to be very sensitive to unexpected shocks in the demand or supply schedules. On the supply side, the generation of electricity may be disturbed by many events, including, for example, power plants going offline due to unexpected technical problems, or changes in weather conditions (particularly relevant for wind and solar power generation). On the demand side, the factors that may disturb the consumption of electricity include, for example, large changes in temperature.

The effect of such shocks on prices depends on the size of the electric power system. In small isolated systems, any disturbance may lead to a large price change. For example, the loss of one generation unit may lead to a large price increase if the remaining number of available units is relatively small. In contrast, in larger power systems the same shocks should be accommodated more easily. For example, if one power plant becomes unavailable, it is more likely that there will be cheap spare capacity in some of the many other units of a large system. Therefore, the enlargement of the electricity system, through a deeper economic and physical integration of neighbouring markets, should lead to prices becoming less sensitive to unexpected shocks in the demand or supply of electricity.

There is an ongoing trend of deregulation and integration of electricity markets in Europe and North America. This change in market structure has naturally affected the interaction between agents and has contributed to an increasing commoditization of electric power. In Europe in particular, as individual national markets move towards a single integrated European market, we should expect, according to our hypothesis, that electricity prices become more resilient to disturbances in the demand or generation functions.

This paper focuses on one specific market, the Iberian Electricity Market (MIBEL). Portugal and Spain have been liberalizing their electricity sectors since the 1990s. Market coupling between Portugal and Spain started in 2007, with one single exchange (OMIE) centralizing the spot power trading for the two countries. The degree of integration between the two countries has increased since then, that is, prices have become more similar, due to two factors. First, the transmission system operators (REN in Portugal and REE in Spain) have been increasing the physical interconnection capacity between the two countries. Second, there has been an increase in renewable energy generation, which has a less appreciated effect on market integration through the reduction of residual demand. MIBEL has thus been evolving from two mostly independent markets to a strongly integrated single market. Furthermore, MIBEL can be seen as an almost isolated system, as the 
interconnection capacity between Spain and France represents a very small fraction of the total MIBEL capacity. It is thus possible to clearly identify the integration stages of MIBEL, which makes this market a good setting to study the effects of market integration on the properties of electricity spot prices (section 2 provides further details on the structure of MIBEL and discusses these effects in detail).

Herein, we assess the persistence of electricity prices in the Iberian market and test whether it has changed through time. Analysing the persistence of electricity prices is meaningful in that it helps to understand the impact of shocks to prices (see Weron (2002), Koopman et al. (2007), Uritskaya and Serletis (2008) Alvarez-Ramirez and Escarela-Perez (2010), Haldrup and Nielsen (2006), Haldrup et al. (2010) among others). The more persistent the price series is, the longer lasting the effects of shocks will be, thus preventing the series from returning to any defined level. In contrast, if prices are strongly mean reverting, the effects of shocks will fade away quickly.

Furthermore, it has been observed that economic and financial variables may display changes in persistence, switching from less to more persistent behavior, or vice-versa (see, for instance, McConnell and Perez-Quiros (2000), Herrera and Pesavento (2005), Cecchetti, Flores-Lagunes and Krause (2006), Kang, Kim and Morley (2009), Halunga, Osborn and Sensier (2009) and Martins and Rodrigues (2014)). In particular, we analyse whether electricity price persistence has changed with the Iberian market integration. According to our hypothesis, as MIBEL becomes more integrated, prices should become less persistent.

We focus on the persistence of the time series of day-ahead electricity prices by analyzing the memory parameter. We consider each hour of the day separately, that is, we analyze 24 time-series of day-ahead hourly prices for Portugal and another 24 series for Spain. By conducting the recently proposed test of Hassler and Meller (2014) we search for breaks in persistence. Bearing in mind that estimation uncertainty is always involved in empirical work, we provide confidence intervals for the memory parameter for the periods before and after the break date. Furthermore, as the break date is also not determined with certainty, we extend the approach of Elliott and Mueller (2007) to compute confidence intervals for the break date. To the best of our knowledge, this is the first study that formally assesses the presence of a break in the persistence of electricity prices.

We find results consistent with the hypothesis that market integration leads to a decrease in the persistence of the price process. More precisely, the tests detect a break in the memory parameter of most price series around the year 2009, which coincides with a significant increase in the integration of Portuguese and Spanish markets (as described in section 2). The memory parameter decreases from an average value (across all series) of 0.8 before the break date to an average value of 0.45 after the break date. These results constitute strong evidence of a noteworthy reduction of electricity price persistence implying 
a substantial change in the speed of absorption of shocks to the electricity market. The results reinforce the view that the Iberian market integration had an impact in the way the electricity market operates.

The remainder of the paper is organized as follows. Section 2 provides a detailed description of the Iberian market integration process, section 3 describes the econometric methodology pursued, section 4 discusses the data and the empirical results, and finally, section 5 concludes.

\section{Overview of market integration and its impact on price dynamics}

The Iberian market (MIBEL) is just one example of a larger trend of market integration. We start by describing this broader context of market integration and the expected impact on the persistence of electricity prices. We then focus on MIBEL, discussing in detail how MIBEL has become more integrated over time. In addition to interconnection capacity, renewables have also played an important role.

\subsection{Global trend of electricity market integration}

The electricity sectors around the world underwent major changes over the recent past and are still changing. In many countries and regions, well established monopolies have been progressively replaced by deregulated markets fostering price competition and promoting market transactions and efficiency. At the same time, there has been a trend towards integrating neighbouring electricity markets, with the goal of increasing competition and the security of supply and de-carbonization of the power sector. Integration usually involves a "market coupling" mechanism, which results in the same electricity price in two adjacent markets during the hours when there is enough transmission capacity between the two markets.

One of the first electricity markets to be liberalized was the UK in 1990. The first multinational integrated market, the Nord Pool, was formed by Norway, Sweden, Finland, and Denmark during the 1990s, and later joined by the Baltic countries of Estonia, Latvia, and Lithuania. The Central Western European (CWE) region has followed the same trend of deregulation and integration. Market coupling between Belgium, France, and the Netherlands started in 2006, and in 2010 between Germany, Austria and France. Just in April 2015, the two major power exchanges in CWE (EPEX Spot and APX Group) announced their intention to integrate their businesses. Since 2014/2015, market coupling has been extended from CWE to the Nord Pool, the UK, Italy, Slovenia, and the Iberian Peninsula (Portugal and Spain). In fact, the whole European Union is moving towards a single integrated European electricity market. 
In the United States, deregulation started in 1992, but has been evolving at different paces across the country. Today, there are several liberalized regional markets, with each market encompassing one or more states. One example of a large competitive integrated market is the PJM Interconnection, which covers 13 states in the East coast plus the District of Columbia. ${ }^{1}$ However, many states still have non-competitive regulated markets, operated by state-owned utilities.

\subsection{The potential effect of integration on electricity prices}

Our main hypothesis is that when two electricity markets become more integrated, the price series should become less persistent. In other words, shocks to prices should have shorter effects, that is, the memory of the price series should decrease. For an intuitive justification of why this should be the case, consider the following examples.

As a first example, consider the case where a base load power plant unexpectedly goes off-line and becomes unavailable for a few days. In an extreme case with two completely separated markets, this event would lead to a price increase in the affected region due to the more expensive peak units that would have to replace the off-line plant, and this shock to prices would likely persist for several days until the plant was repaired. In the other extreme case of two strongly integrated markets, the lack of one power plant in one region could be cheaply compensated by small ramp ups in several units in the other region. Thus, the price shock would be both smaller and less persistent.

As a second example, consider an abnormal peak in demand and a resulting increase in price. Suppose that this increase in demand requires dispatching a peaking hydropower plant at full capacity over a long period. The water in the reservoir drops to low levels, which leads the plant to withdraw from the market in the following periods to preserve water. In separated markets, the peak-hour prices would likely remain high for some time, as the following peak consumptions would probably have to be met by other less efficient and more expensive peaking units (e.g., diesel generators). In contrast, in a larger integrated market, it is more likely that less expensive generators would be available in the following peak periods, thus quickly returning prices to normal levels.

1. PJM Interconnection is a regional transmission organization that coordinates the movement of wholesale electricity in Delaware, Illinois, Indiana, Kentucky, Maryland, Michigan, New Jersey, North Carolina, Ohio, Pennsylvania, Tennessee, Virginia, West Virginia and the District of Columbia. 


\subsection{The integration of the Iberian electricity market}

We test our hypothesis on the Iberian Electricity Market (MIBEL). This market was created in July 2007, when Portugal and Spain joined their electricity markets. Since then, firms on both sides of the border submit their bids to sell or buy in a common pool, which is cleared through a standard non-discriminatory auction. The market operates in a fully liberalized, competitive setting. As long as the transmission capacity is sufficient, the price is the same in both markets, i.e., there is market coupling.

When the prices are the same in both markets at all times, we say that the markets are perfectly integrated. Hence, one can consider that market integration has increased when an increase in the number of hours of market coupling is observed.

Figure 1 shows the fraction of hours during which the Portuguese and Spanish markets are coupled. ${ }^{2}$ At the beginning of MIBEL, from 2007 until the end of 2008, markets were coupled only during a small fraction of the time (around $32 \%$ of the daily hours). In contrast, since 2009 the markets have been coupled most of the time (around $84 \%$ of the daily hours). In particular, in the first quarter of 2009 an impressive increase in the duration of market coupling is observed, i.e., an increase from $32 \%$ to $75 \%$ of the hours. MIBEL is thus an interesting setting to study the effect of market integration on prices because we can identify a clear, almost discrete, significant increase in the degree of integration.

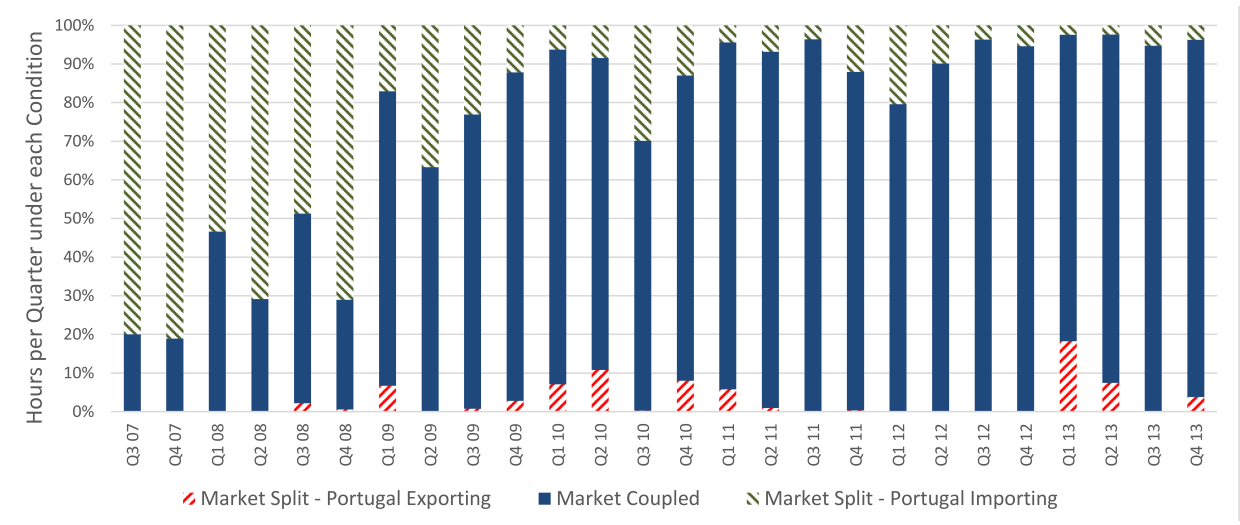

Figure 1: Fraction of time under market coupling or splitting

Additionally, MIBEL is also an interesting setting because it is a relatively small isolated system, in the sense that the interconnection with France can only provide a very small fraction of the consumption in MIBEL. For example, the

2. Price data for both markets is available at www.omip.pt 
average load in MIBEL during November 2014 (the end of our sample period) was $24459 \mathrm{MW}$, while the nominal interconnection capacity between Spain and France was $1400 \mathrm{MW}$. We can thus analyze the integration between Portugal and Spain, while safely ignoring electricity exchanges with other markets.

\subsection{Factors behind MIBEL's integration}

Before proceeding to the formal econometric test of our hypothesis, we first analyze the underlying factors that caused the increase in MIBEL's integration. The only constraint on coupling is the actual physical cross-border power transmission capacity, which can become congested if too much power is assigned to it. In that case, the auction is redone considering split markets, with an extra buy bid on the exporting side and an extra sell offer on the importing side, both with a size equal to the transmission capacity and a price equal to the exporting country's final price. The day-ahead prices in the two countries become different for that particular hour when the interconnection is congested.

Figure 1 also shows the fraction of hours when there is market splitting, either due to exhaustion of the transmission capacity from Spain to Portugal or in the other direction. The most common case is by far splitting due to exhaustion of the transmission capacity from Spain to Portugal (i.e., Portugal is importing), which results in market-clearing prices being higher in Portugal. Hence, to understand the trend of increasing market coupling described above, we focus on the reasons that allowed for a reduction of the hours when Portugal exceeded its import capacity.

We argue that the growth of market coupling is due to two main factors. The first and more obvious factor is an increase in the nominal cross-border physical transmission capacity. Market splitting produces a congestion rent, which is kept by the TSOs to support precisely the enlargement of crossborder capacities and the integration of MIBEL. The first enlargement was in December 2009, when two lines were replaced by more modern ones $(220 \mathrm{kV})$, followed by further increases in December 2010 with the addition of an 8th $400 \mathrm{kV}$ line and replacement of two older $220 \mathrm{kV}$ lines. ${ }^{3}$

The second factor is less obvious in the sense that the effect comes through a reduction in the number of hours when the efficient market outcome would be to transfer energy from Spain to Portugal in excess of the transmission capacity,

3. Note however that the actual capacity of the transmission lines is a function not only of the nominal transmission capacity, but also of several constraints, such as air temperature or the state of the each countries' own transmission network. Furthermore, the programmed availability of renewable energies also has an effect on the maximum transmission capacity the TSOs make available. 
i.e., a reduction in splitting with Portugal importing. This factor is the growth in renewable energy power in Portugal, most notably wind.

In order to promote a transition to more sustainable energy sources, the Portuguese government created a "Special Regime", which basically consists of a feed-in-tariff and dispatch priority for produced electricity. This remuneration scheme has been very effective in attracting investments and the last few years have seen a determined growth in installed capacity from renewable sources. As detailed in Figure 2, wind generation increased from less than $10 \%$ of demand in 2007 to around 24\% of demand in 2013. Considering also other "Special Regime" producers (Combined Heat and Power, run-of-river, and solar PV), the total amount of renewable energy increased from around $20 \%$ of demand in the beginning of the market to close to $50 \%$ in $2013 .{ }^{4}$

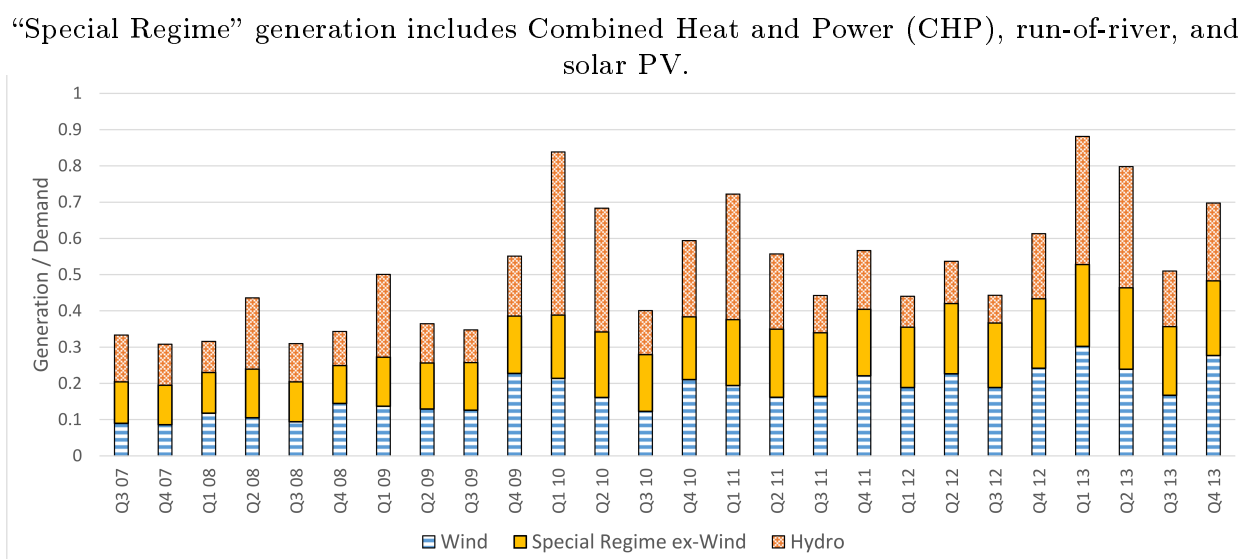

Figure 2: The growth of renewable power production in Portugal

The fact that "Special Regime" production has dispatch priority implies a reduction in the fraction of demand that is left and needs to be satisfied in the market, that is, the residual demand decreases. The result is that the "remaining" market becomes more integrated: since there is an increase in the ratio of Portuguese import capacity to residual demand, the same transmission capacity can accommodate more Spanish bidders (relative to the actual Portuguese residual demand) before being forced to uncouple. In other words, renewable generation under the "Special Regime" has an indirect influence on market coupling by decreasing the amount of power that is actually traded in the market.

In addition to these two factors that contributed to market coupling growth, there is also a third factor of a more seasonal nature - large dam hydropower generation. Hydropower, although not subject to the special regime

4. Hourly generation data was provided by REN. 
conditions, plays nevertheless an important role in the coupling of the markets. Hydropower has two important characteristics. First, given available water, it is dispatchable, that is, the plant can choose when to produce. Second, since hydropower has no variable fuel costs, the producer can freely chose the price at which to offer the electricity.

In times of abundant water in Portugal, hydropower will tend to enter the market at a very low price, which has an effect similar to other renewable generators, thus also contributing to a decrease in imports into Portugal. This effect can be seen by comparing Figures 1 and 2. An increase in hydropower production generally leads to an increase in the amount of hours during which the market is coupled and, in some quarters, it even leads to Portugal increasing its exports to the point of splitting the market to its benefit. In particular, the first two quarters of 2010 stand out from the previous quarters as being particularly strong in hydro production.

The increase in nominal transmission capacity together with the increase in renewable power generation clearly moved MIBEL towards a deeper integration state which could have led to changes in the persistence of the price processes.

\section{Testing for breaks in persistence}

To illustrate the methodology used to investigate possible persistence changes in the electricity prices, $p_{t}$, consider that $p_{t}$ is generated by a fractionally integrated process with no break, such as,

$$
(1-L)^{d+\theta} p_{t}=\varepsilon_{t} I(t \geq 1), t=1,2, \ldots, \varepsilon_{s}=0 \text { for all } s \leq 0
$$

where $I($.$) is an indicator variable, \left\{p_{t}\right\}$ are the electricity prices, $L$ denotes the usual lag operator, $(d, \theta)^{\prime}$ is a real-valued vector, and $\left\{\varepsilon_{t}\right\}$ is a stationary and invertible short-memory process integrated of order zero, $\mathrm{I}(0)$, such that $\varepsilon_{t}:=\sum_{k=0}^{\infty} \gamma_{k} \xi_{t-k}, \xi_{t}$ is a zero mean white noise innovation and $\sum_{k=0}^{\infty} \gamma_{k}<\infty$ and different from zero (which follows from the $\mathrm{I}(0)$ property of $\varepsilon_{s}$ ). For a pre-specified value $d$, typically the aim is to test the null hypothesis that $\left\{p_{t}\right\}$ is fractionally integrated of order $d$, denoted as $\mathrm{FI}(d)$ i.e., testing $\mathrm{H}_{0}: \theta=0$ against $\mathrm{H}_{1}: \theta \neq 0$. The standard unit-root case, $d=1$, is nested as a particular case in this generalized context.

Hence, to implement the test procedure proposed by Breitung and Hassler (2002) and Demetrescu et al. (2008), consider $\left\{\varepsilon_{t, d}\right\}$ a series resulting from differencing $\left\{p_{t}\right\}$ under the null hypothesis, namely, $\varepsilon_{t, d}:=(1-L)^{d} y_{t}$, where the fractional difference operator, $\Delta^{d}:=(1-L)^{d}$, is characterized by the formal 
binomial expansion:

$\Delta^{d}:=\sum_{j=0}^{\infty} \pi_{j}(d) L^{j}, \quad$ with $\pi_{0}(d):=1$ and $\pi_{j}(d):=\frac{j-1-d}{j} \pi_{j-1}(d), j>0$.

Moreover, given $\left\{\varepsilon_{t, d}\right\}$, define the filtered process $x_{t-1, d}^{*}:=\sum_{j=1}^{t-1} j^{-1} \varepsilon_{t-j, d}$, $t=2, \ldots, T$. The particular form of $\left\{x_{t-1, d}^{*}\right\}$, characterized by an harmonic weighting of the lags of $\left\{\varepsilon_{t, d}\right\}$, results from the expansion of $\log (1-L)^{d}$ which features the partial derivative of the (Gaussian) log-likelihood function of $\left\{p_{t}\right\}$ under the null hypothesis. As a result, $\left\{x_{t-1, d}^{*}\right\}$ is core in the construction of regression based LM-type tests.

Hence, given the variables $\left(\varepsilon_{t, d}, x_{t-1, d}^{*}\right)^{\prime}$ introduced previously, we consider the following auxiliary regression in order to determine whether $\mathrm{H}_{0}: \varphi=0$ holds true:

$$
\varepsilon_{t, d}=\varphi x_{t-1, d}^{*}+\sum_{j=1}^{K} a_{j} \varepsilon_{t-j, d}+u_{t}, t=K+1, \ldots, T
$$

where following Demetrescu et al. (2008) the $K$ lags of the dependent variable, $\varepsilon_{t-i, d}, i=1, \ldots, K$, are included to accommodate the short-memory properties of the series, i.e., to provide serial correlation free residuals. Furthermore, for the choice of $K$, Demetrescu et al. (2008) recommend the use of the rule proposed by Schwert (1989), i.e., $K:=\left[4(T / 100)^{1 / 4}\right]$.

Breitung and Hassler (2002) and Demetrescu et al. (2008) show that the squared $t$-statistic for $\mathrm{H}_{0}: \varphi=0$ given the OLS estimate $\widehat{\varphi}$ from $(3)$, denoted $L M_{L S}$ in the sequel, is asymptotically equivalent to the LM test for $\mathrm{H}_{0}: \theta=0$. The LM test was shown to be efficient under Gaussianity by Robinson (1994) and Tanaka (1999).

Under $\mathrm{H}_{0}: \varphi=0, x_{t-1, d}^{*}$ is (asymptotically) stationary and admits the causal representation $x_{t-1, d}^{*}=\sum_{j=0}^{t-1} \varphi_{j} v_{t-j-1}$, where $\left\{\varphi_{j}\right\}_{j \geq 0}$ is a square (but not absolutely) summable sequence independent of the value of $d$, and $L M_{L S}$ is asymptotically distributed as a Chi-squared distribution with one degree of freedom, denoted $\chi_{(1)}^{2}$. Under the sequence of local alternatives $\varphi=c / \sqrt{T}$, $c \neq 0$, the general characterization $\varepsilon_{t, d}=(c / \sqrt{T}) x_{t-1, d+\theta}^{*}+\varepsilon_{t}+o_{p}(1)$ holds true (Tanaka 1999; Demetrescu et al. 2008; and Hassler et al. 2009) and it follows that $x_{t-1, d}^{*}=x_{t-1, d+\theta}^{*}+(c / \sqrt{T}) \sum_{j=1}^{t-1} j^{-1} x_{t-1-j, d+\theta}^{*}+o_{p}(1)$, with $x_{t-1, d+\theta}^{*}=\sum_{j=0}^{t-1} \varphi_{j} v_{t-j-1}$. As a result, $\varphi=c / \sqrt{T}$ captures the extent and the direction of the departure from the null, with positive (negative) values of $\varphi$ indicating larger (smaller) orders of integration than $d$. Hence, testing the fractional integration hypothesis on the basis of (3) ensures non-trivial power against local alternatives; see Demetrescu et al. (2008). 
However, given the focus of this paper, as an alternative to (1) we consider instead, the more general approach proposed by Hassler and Meller (2014, p.656), which considers a process with $m+1$ regimes. In particular, we consider that the persistence of electricity prices may change over time, i.e., that electricity prices are generated as,

$$
(1-L)^{d+\theta_{j}} p_{t}=\varepsilon_{t},
$$

where $t=T_{j-1}+1, \ldots, T_{j}, j=1, \ldots, m+1, T_{0}=0, T_{m+1}=T$ and $\theta_{j}$ denotes the shift in persistence occurring at the $\mathrm{j}^{\text {th }}$ break. Thus, the null hypothesis of no breaks is $H_{0}: \theta_{1}=\ldots=\theta_{m}=0$.

The test regression suggested by Hassler and Meller (2014) corresponds to (3) but is augmented with a set of break dummies, $D_{t}\left(\lambda_{j}\right)$, such as,

$$
\varepsilon_{t, d}=\varphi x_{t-1, d}^{*}+\sum_{j=1}^{m} \psi_{j} x_{t-1, d}^{*} D_{t}\left(\lambda_{j}\right)+\sum_{i=1}^{p} \beta_{i} \varepsilon_{t-i, d}+\varepsilon_{p t} .
$$

where the break dummies used in (5) are defined as,

$$
D_{t}\left(\lambda_{j}\right)=\left\{\begin{array}{ccc}
1 & \text { if } & t=\left[\lambda_{j} T\right]+1, \ldots,\left[\lambda_{j+1} T\right] \\
0 & \text { if } & \text { otherwise }
\end{array}\right.
$$

However, given that the true break fractions are not known, $\lambda_{j}$ may not necessarily correspond to the true break fraction $\lambda_{j}^{0}$. The multiple change analysis is then performed based on Bai and Perron's (1998) methodology.

It is also important for the empirical applications to assume that each sample segment has a minimal length determined by a trimming parameter $\varepsilon>0$, i.e.,

$$
\frac{T_{j}-T_{j-1}}{T} \geq \varepsilon, j=1, \ldots, m+1 .
$$

The limiting distributions of the tests depend on the trimming considered, and Bai and Perron (2003) recommend the usage of $\varepsilon=0.15$ in order to have better size properties in finite samples. In this paper, and following Hassler and Meller (2014), we also consider a trimming parameter of $\varepsilon=0.15$, and make use of the critical values in Bai and Perron (2013).

The F-statistics $F\left(\lambda_{1}, \ldots, \lambda_{m}\right)$ for testing $H_{0}: \psi_{1}=\ldots=\psi_{m}=0$ in (5) are computed for all possible break points subject to,

$$
\Lambda_{\varepsilon}=\left\{\left(\lambda_{1}, \ldots, \lambda_{m}\right):\left|\lambda_{j}-\lambda_{j-1}\right| \geq \varepsilon, j=1, \ldots, m+1\right\}, \lambda_{0}=0, \lambda_{m+1}=1 .
$$

Hence, the persistence change test statistic is thus, the maximum across all $F$ statistics,

$$
\sup F(m):=\max _{\Lambda_{\varepsilon}}\left(F\left(\lambda_{1}, \ldots, \lambda_{m}\right)\right)
$$


which can easily be determined by a grid search for moderate sample sizes and small $m$. For large $m$, Bai and Perron (2003) recommend a dynamic programming approach. Critical values are available up to $m=9$. For $m=1$ this corresponds to a max-Chow test in line with Andrews (1993). The candidates for breaks are the arguments maximising $\sup F(m)$ (or equivalently the arguments minimising the sum of squared residuals from (5)),

$$
\left(\widehat{\lambda}_{1}, \ldots, \widehat{\lambda}_{m}\right)=\underset{\Lambda_{\varepsilon}}{\arg \max }\left(F\left(\lambda_{1}, \ldots, \lambda_{m}\right)\right) .
$$

A further important feature that will also prove useful in the empirical application next is the computation of confidence intervals for the break dates. To set up the confidence intervals we follow the approach of Elliott and Mueller (2007) and compute (5) over $\lambda \in(0.15,0.85)$. In other words, we run test regression (5) with the dummy variable defined for all possible dates $[\lambda T]$, with $\lambda \in(0.15,0.85)$. Thus, defining $F(\lambda)$ as the test statistic for $H_{0}: \psi=0$ we define the break date confidence interval as follows. For each $F(\lambda)>C V_{1-\alpha}$ for $\lambda \in(0.15,0.85)$ we include a break date in the $\alpha$ level confidence set and exclude it otherwise, where $C V_{1-\alpha}$ is the level $(1-\alpha)$ critical value of the $F(\lambda)$ statistic.

\section{Empirical Analysis}

In this section, we apply the econometric methodology described in section 3 to the hourly electricity prices in Portugal and Spain. For both countries, we present the value of the test statistic (6) along with a statistical significance assessment as well as the corresponding break date. We also report the persistence of hourly electricity prices for the sample periods before and after the break date as well as for the whole sample.

\subsection{Data}

We collect day-ahead hourly spot prices for the MIBEL wholesale electricity market from 1/July/2007 (the market starting day) until 8/Dec/2014. The data include prices for both Portugal and Spain. When there is enough transmission capacity between the two markets, the prices are the same, that is, there is market coupling. Otherwise, the markets split and each country trades at a different price. Hence, we analyze the Portuguese series independently from the Spanish ones.

As in most markets, the auction in MIBEL sets an independent price for each hour of the day. Therefore, we study each of the 24 hourly price series in each country. An alternative approach would be to average prices for some hours of the day (for example, night time versus day time), but that would 
require a somewhat arbitrary classification of the hours. By looking at each hourly price separately, we are able to obtain a more detailed characterization of the data.

Since the average electricity price varies across the week and throughout the year due to changes in electricity demand, weekly and yearly seasonality are addressed using week day $\left(d_{i}, i=1, \ldots, 7\right)$ and monthly $\left(m_{k}, k=1, \ldots, 12\right)$ dummy variables. Hence, the adjusted price series is computed as

$$
p_{t}=p_{t}^{*}-\widehat{c}-\sum_{i=2}^{7} \widehat{\varphi}_{i} d_{i t}-\sum_{k=2}^{12} \widehat{\psi}_{k} m_{k t}
$$

where $p_{t}^{*}$ is the observed electricity log price series, $\widehat{c}$ corresponds to the estimate of the intercept, and $\widehat{\varphi}_{i}, i=2, \ldots, q$, and $\widehat{\psi}_{k}, k=2, \ldots, 12$, to the slope parameter estimates of the week day and monthly regressors.

\subsection{Empirical Results}

4.2.1. Prices in the Portuguese market. Table 1 displays the results for the Portuguese case. We find that for all hours there is a statistically significant persistence break. The break date is always determined to have occurred in the year of 2009, which is consistent with the discussion in section 2 documenting a strong increase in market integration in 2009.

Furthermore, the break occurred earlier for the night-time hours of low demand (from 2:00 to 6:00) than for the day-time hours of peak demand (from 7:00 to 20:00). This result is also consistent with the discussion in section 2. During the night, not only total demand is naturally low, but also wind generation is typically stronger. Hence, the ratio of transmission capacity to residual demand will be particularly high during these hours. The market should thus couple more often during night-time periods. Hence, the fact that the memory breaks occur earlier for night-time prices is also consistent with our hypothesis that higher integration leads to lower price memory.

Table 1 also presents the estimates for the memory parameter, before and after the break, while Figure 3 displays the corresponding confidence intervals. Before the break date, electricity prices were non-stationary, that is, $0.5<d<1$ for all hours, ranging from 0.68 up to 0.92 . In contrast, after the break, most electricity prices are stationary $(0<d<0.5)$ with a substantially lower memory. The decrease in persistence is noteworthy attaining on average 0.35 . Furthermore, the reduction is slightly higher for night-time hours $(0.36)$ than for day-time hours (0.33).

One should highlight that restricting the analysis to the full sample memory estimates would be misleading as one would conclude that electricity prices are non-stationary. By allowing for a break in the memory parameter one can detect persistence changes stemming from the deepening of the Iberian market integration which enhance the understanding of the electricity price behavior. 
Working Papers

\begin{tabular}{|c|c|c|c|c|c|c|c|c|c|}
\hline \multirow[b]{2}{*}{ Hour } & \multirow{2}{*}{$\begin{array}{c}\text { Test } \\
\text { statistic }\end{array}$} & & \multicolumn{3}{|c|}{ Break date } & \multicolumn{4}{|c|}{$\widehat{d}$} \\
\hline & & & Year & Month & Day & Full sample & Before break & After break & Change \\
\hline 1 & 21.56 & $* * *$ & 2009 & 7 & 23 & 0.55 & 0.85 & 0.46 & -0.39 \\
\hline 2 & 20.25 & $* * *$ & 2009 & 7 & 8 & 0.53 & 0.92 & 0.43 & -0.49 \\
\hline 3 & 22.21 & $* * *$ & 2009 & 2 & 5 & 0.51 & 0.84 & 0.43 & -0.41 \\
\hline 4 & 21.76 & $* * *$ & 2009 & 2 & 10 & 0.52 & 0.83 & 0.43 & -0.39 \\
\hline 5 & 26.55 & $* * *$ & 2009 & 2 & 5 & 0.47 & 0.75 & 0.39 & -0.36 \\
\hline 6 & 28.66 & $* * *$ & 2009 & 2 & 10 & 0.55 & 0.88 & 0.46 & -0.42 \\
\hline 7 & 25.01 & $* * *$ & 2009 & 8 & 2 & 0.54 & 0.80 & 0.44 & -0.37 \\
\hline 8 & 14.87 & $* * *$ & 2009 & 11 & 8 & 0.57 & 0.75 & 0.47 & -0.28 \\
\hline 9 & 12.19 & $* *$ & 2009 & 11 & 8 & 0.53 & 0.78 & 0.40 & -0.37 \\
\hline 10 & 12.85 & $* * *$ & 2009 & 11 & 8 & 0.55 & 0.68 & 0.42 & -0.26 \\
\hline 11 & 18.28 & $* * *$ & 2009 & 11 & 8 & 0.59 & 0.75 & 0.47 & -0.28 \\
\hline 12 & 22.51 & $* * *$ & 2009 & 11 & 8 & 0.56 & 0.79 & 0.46 & -0.34 \\
\hline 13 & 30.06 & $* * *$ & 2009 & 12 & 8 & 0.58 & 0.78 & 0.45 & -0.33 \\
\hline 14 & 24.34 & $* * *$ & 2009 & 11 & 8 & 0.57 & 0.81 & 0.44 & -0.37 \\
\hline 15 & 21.48 & $* * *$ & 2009 & 11 & 8 & 0.54 & 0.79 & 0.44 & -0.35 \\
\hline 16 & 27.52 & $* * *$ & 2009 & 11 & 8 & 0.56 & 0.77 & 0.45 & -0.31 \\
\hline 17 & 19.58 & $* * *$ & 2009 & 11 & 8 & 0.53 & 0.77 & 0.40 & -0.37 \\
\hline 18 & 17.21 & $* * *$ & 2009 & 11 & 8 & 0.59 & 0.81 & 0.47 & -0.34 \\
\hline 19 & 16.66 & $* * *$ & 2009 & 7 & 22 & 0.62 & 0.85 & 0.50 & -0.35 \\
\hline 20 & 17.05 & $* * *$ & 2009 & 11 & 4 & 0.58 & 0.77 & 0.45 & -0.31 \\
\hline 21 & 23.55 & $* * *$ & 2009 & 2 & 6 & 0.62 & 0.74 & 0.55 & -0.19 \\
\hline 22 & 19.82 & $* * *$ & 2009 & 1 & 23 & 0.62 & 0.82 & 0.52 & -0.30 \\
\hline 23 & 12.24 & $* *$ & 2009 & 9 & 4 & 0.65 & 0.86 & 0.52 & -0.34 \\
\hline 24 & 11.98 & $* *$ & 2009 & 8 & 21 & 0.63 & 0.90 & 0.51 & -0.39 \\
\hline
\end{tabular}
respectively.

TABle 1. Memory break for Portuguese hourly electricity prices 


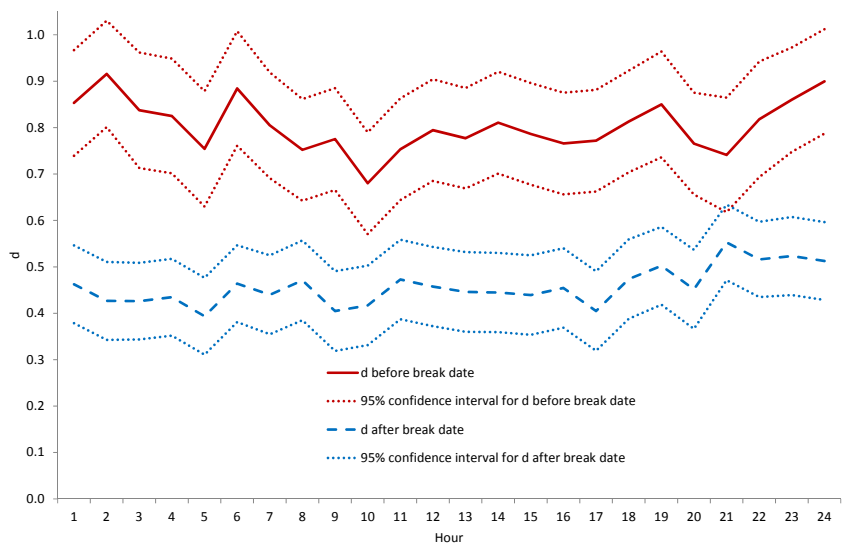

Figure 3: Confidence intervals for $\mathrm{d}$ before and after the break in Portugal

4.2.2. Prices in the Spanish market. Table 2 and Figure 4 report the corresponding results for Spain. We find a statistically significant break for most hours. Only in a small number of hours (from 10:00 to 13:00 and from 22:00 to 24:00), do we not reject the null hypothesis of no break in memory at the 5 per cent significance level. In the case of Spain, most of the breaks occurred in the second half of 2009. Nonetheless, the breaks occurred earlier for most night-time prices, similarly to the Portuguese case.

Likewise in Portugal, the decrease is slightly higher for night-time hours (0.34) than for day-time hours (0.30). The average reduction in the memory parameter is 0.32 which is slightly lower than the one recorded for the Portuguese case which suggests that the impact of the Iberian market integration was slightly higher in the latter case. Such a result may reflect the fact that the Portuguese market is smaller than the Spanish market and therefore potentially more influenced by the market integration process.

As in the Portuguese case, looking at the full sample can be misleading as one would be tempted to conclude that electricity prices are non-stationary. In fact, although before the break date, prices are non-stationary with the memory parameter ranging from 0.66 to 0.87 , after the break, we find that most of the prices become stationary presenting a substantially lower persistence. 
Working Papers

\begin{tabular}{|c|c|c|c|c|c|c|c|c|c|}
\hline \multirow{3}{*}{$\begin{array}{c}\text { Hour } \\
1\end{array}$} & \multirow{2}{*}{\multicolumn{2}{|c|}{$\begin{array}{c}\text { Test } \\
\text { statistic }\end{array}$}} & \multicolumn{3}{|c|}{ Break date } & \multicolumn{4}{|c|}{$\widehat{d}$} \\
\hline & & & Year & Month & Day & Full sample & Before break & After break & Change \\
\hline & 10.48 & ** & 2009 & 9 & 27 & 0.52 & 0.75 & 0.42 & -0.32 \\
\hline 2 & 18.03 & $* * *$ & 2009 & 7 & 29 & 0.52 & 0.84 & 0.41 & -0.43 \\
\hline 3 & 29.52 & $* * *$ & 2008 & 11 & 15 & 0.47 & 0.77 & 0.39 & -0.38 \\
\hline 4 & 23.39 & $* * *$ & 2008 & 11 & 11 & 0.48 & 0.76 & 0.42 & -0.34 \\
\hline 5 & 24.93 & $* * *$ & 2008 & 8 & 15 & 0.45 & 0.78 & 0.41 & -0.37 \\
\hline 6 & 25.34 & $* * *$ & 2008 & 8 & 13 & 0.48 & 0.82 & 0.44 & -0.38 \\
\hline 7 & 31.58 & $* * *$ & 2008 & 9 & 10 & 0.52 & 0.83 & 0.48 & -0.36 \\
\hline 8 & 11.38 & $* *$ & 2009 & 11 & 6 & 0.55 & 0.66 & 0.47 & -0.19 \\
\hline 9 & 12.53 & $* * *$ & 2009 & 10 & 10 & 0.53 & 0.69 & 0.45 & -0.24 \\
\hline 10 & 8.21 & $*$ & 2009 & 11 & 5 & 0.54 & 0.75 & 0.43 & -0.32 \\
\hline 11 & 2.42 & & 2009 & 11 & 6 & 0.57 & 0.72 & 0.48 & -0.24 \\
\hline 12 & 5.57 & & 2009 & 11 & 6 & 0.55 & 0.75 & 0.45 & -0.30 \\
\hline 13 & 7.19 & $*$ & 2009 & 12 & 6 & 0.56 & 0.77 & 0.43 & -0.34 \\
\hline 14 & 14.56 & $* * *$ & 2009 & 11 & 6 & 0.55 & 0.75 & 0.43 & -0.31 \\
\hline 15 & 23.22 & $* * *$ & 2009 & 11 & 6 & 0.50 & 0.70 & 0.41 & -0.29 \\
\hline 16 & 23.02 & $* * *$ & 2009 & 11 & 6 & 0.53 & 0.69 & 0.43 & -0.27 \\
\hline 17 & 23.26 & $* * *$ & 2009 & 11 & 6 & 0.50 & 0.72 & 0.41 & -0.31 \\
\hline 18 & 18.22 & $* * *$ & 2009 & 11 & 6 & 0.56 & 0.75 & 0.45 & -0.30 \\
\hline 19 & 17.41 & $* * *$ & 2009 & 10 & 23 & 0.59 & 0.81 & 0.46 & -0.35 \\
\hline 20 & 24.37 & $* * *$ & 2009 & 11 & 4 & 0.57 & 0.80 & 0.41 & -0.39 \\
\hline 21 & 12.16 & $* *$ & 2009 & 1 & 27 & 0.60 & 0.77 & 0.52 & -0.25 \\
\hline 22 & 3.82 & & 2009 & 1 & 4 & 0.60 & 0.87 & 0.50 & -0.37 \\
\hline 23 & 7.66 & $*$ & 2010 & 3 & 31 & 0.60 & 0.76 & 0.44 & -0.32 \\
\hline 24 & 2.61 & & 2009 & 11 & 24 & 0.62 & 0.87 & 0.50 & -0.37 \\
\hline
\end{tabular}

TABLE 2. Memory break for Spanish hourly electricity prices 


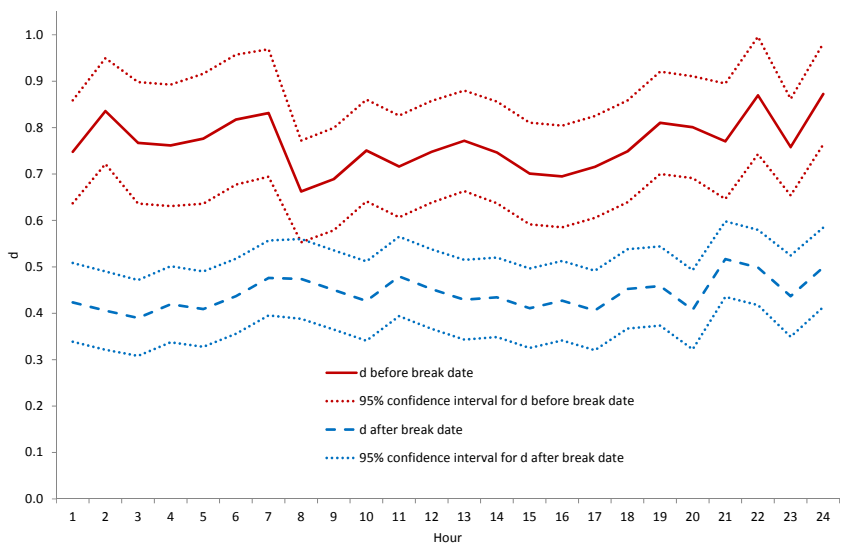

Figure 4: Confidence intervals of $\mathrm{d}$ before and after the break in Spain

\subsection{Robustness analysis}

The results of the previous section indicate that most break dates occurred in 2009 for both Portugal and Spain, the year where we also observe a strong increase in market integration between the two countries. To further stress this point, we pursue a procedure similar to the one proposed by Elliott and Mueller (2007) to construct confidence intervals for the break date, as described in Section 3. Figure 5 presents confidence intervals for the break dates for both cases with a confidence level of 95 per cent. The figure clearly reinforces the finding that there has been a clustering of break dates in 2009. Furthermore, there is a substantial overlap of intervals for Portugal and Spain for any given hour, which suggests that one cannot discard the idea that the breaks occurred simultaneously in both markets.

We also investigated the presence of more than one break in the hourly electricity prices in both countries. Resorting again to the procedure of Hassler and Meller (2014), which in contrast to other procedures also allows for the detection of multiple breaks, we only found strong evidence of one further break for the 21st hour in Portugal (with the break date being 2010-1-1) and for the 7th hour in Spain (with the break date being 2009-11-5). Note that in both cases the break dates are relatively close to the other break dates reported in Tables 1 and 2 and reinforce the finding that there is a cluster of break dates in 2009 . 


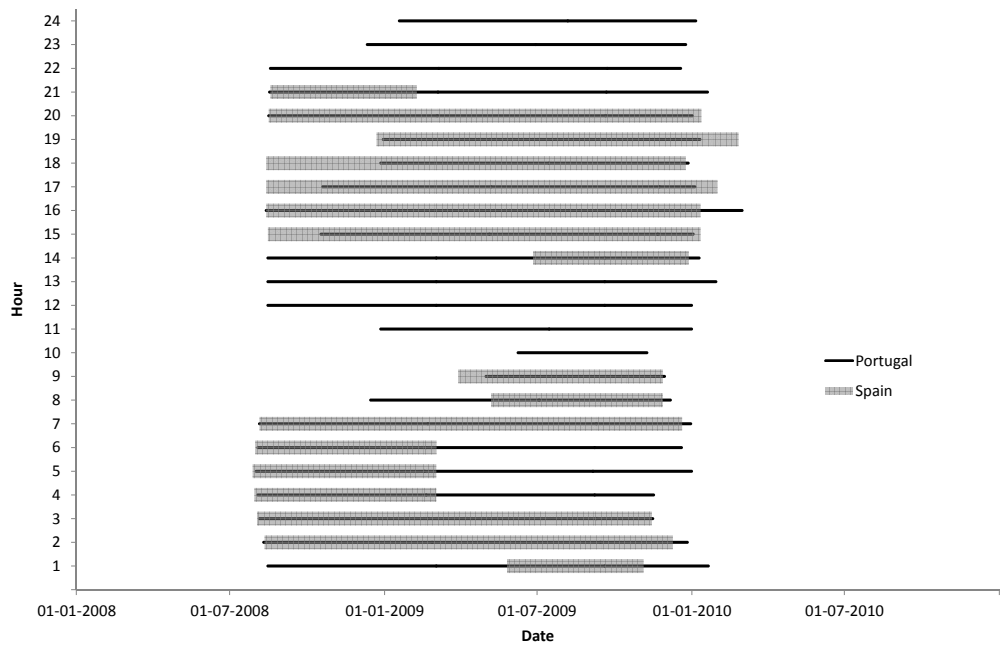

Figure 5: Confidence intervals for break dates in Portugal and Spain

\subsection{Further discussion on the implications of the findings}

For illustrative purposes, Figure 6 presents the impulse response function over the first 365 time periods, say days, computed from a simple fractional integrated process $(1-L)^{d} y_{t}=\varepsilon_{t} I(t \geq 1)$, for $\varepsilon_{t} \sim \operatorname{nid}\left(0, \sigma^{2}\right)$ with $d=0.45$ and $d=0.80$. The choice of $d=0.45$ and $d=0.80$ resulted from the empirical application, since as before the market integration the average $d$ across all daily hours was around $d=0.8$, which decreased considerably after market integration to $d=0.45$. We observe that although both are still significant after 365 periods, the impact of a shock when $d=0.45$ (which corresponds to a stationary long memory process) is much smaller than that resulting when $d=0.80$ (nonstationary process). Note that the slow decay of the impulse response function observed is an intrinsic feature of these fractionally integrated processes. 


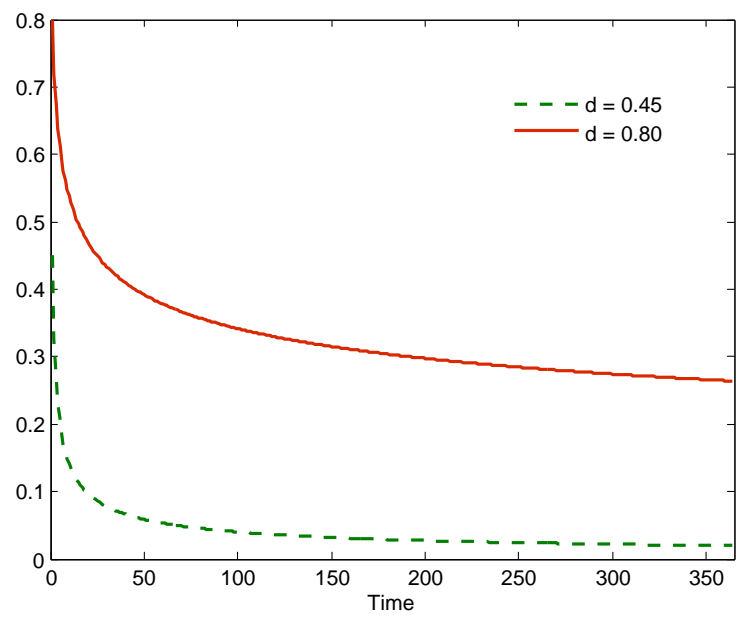

Figure 6: Impulse Response Functions for $\mathrm{d}=0.45$ and $\mathrm{d}=0.8$

Besides the impact in terms of the transmission over time of the shocks to electricity prices, a break in $d$ can also have important implications on the forecasting performance of the models in use (see Weron (2014) for survey). To assess the latter issue, we conduct a Monte Carlo simulation analysis. In particular, we consider the following data generating process for illustrative purposes, $(1-L)^{d_{t}} y_{t}=\varepsilon_{t}, t=1, \ldots, T$ with $\varepsilon_{t} \sim \operatorname{nid}\left(0, \sigma^{2}\right)$ and

$$
d_{t}= \begin{cases}d & \text { if } t<t_{\text {break }} \\ d+c & \text { if } t \geqslant t_{\text {break }}\end{cases}
$$

where $t_{\text {break }}:=\lambda_{0} T$ and $\lambda_{0}$ is the break fraction considered.

That is, in the simulations we consider a gaussian fractional integrated process with a change in $d$ of magnitude $c$ at the break date $t_{\text {break }}$. Suppose that the forecasting model in use, say a gaussian fractional integrated process, assumes the value of $d$ before the break and is used to forecast during the postbreak period. For comparison, let us also consider the same model but with the value of $d+c$ after the break. This exercise allows us to isolate the impact of the only source of misspecification, in this case $d$, in terms of forecasting performance. Hence, one can assess how costly ignoring the presence of a break in $d$ can be or, in other words, how large the forecasting gains of taking on board the knowledge that a break has occurred can be.

In the simulations, we consider a sample size of 3000 observations, which is similar to our sample size, and consider 1000 forecasts in the post-break period. As the forecasting horizon may also matter, we consider forecasting horizons of up to 10 time periods. In terms of the change in $d$, that is $c$, we address both the case where there is a decrease $(c<0)$ as well as the case of an increase $(c>0)$. We also assess the impact of the size of $c$ in terms of 
the forecasting behaviour. For each case, we compute the average ratio, over 1000 simulations, between the Root Mean Square Forecast Error (RMSFE) of the correctly specified model, which considers the value after the break, and the RMSFE of the model that assumes the value before the break. A ratio lower than 1 denotes that the former is better than the latter. The results are presented in Table 3.

\begin{tabular}{r|cccccccccc}
$c$ & \multicolumn{10}{c}{ Forecasting horizon } \\
& 1 & 2 & 3 & 4 & 5 & 6 & 7 & 8 & 9 & 10 \\
\hline 0.5 & 0.57 & 0.84 & 0.90 & 0.93 & 0.95 & 0.96 & 0.97 & 0.97 & 0.98 & 0.98 \\
0.4 & 0.75 & 0.91 & 0.95 & 0.97 & 0.97 & 0.98 & 0.98 & 0.99 & 0.99 & 0.99 \\
0.3 & 0.88 & 0.96 & 0.98 & 0.98 & 0.99 & 0.99 & 0.99 & 0.99 & 0.99 & 0.99 \\
0.2 & 0.96 & 0.98 & 0.99 & 0.99 & 1.00 & 1.00 & 1.00 & 1.00 & 1.00 & 1.00 \\
0.1 & 0.99 & 1.00 & 1.00 & 1.00 & 1.00 & 1.00 & 1.00 & 1.00 & 1.00 & 1.00 \\
-0.1 & 0.99 & 1.00 & 1.00 & 1.00 & 1.00 & 1.00 & 1.00 & 1.00 & 1.00 & 1.00 \\
-0.2 & 0.97 & 0.99 & 0.99 & 0.99 & 1.00 & 1.00 & 1.00 & 1.00 & 1.00 & 1.00 \\
-0.3 & 0.95 & 0.97 & 0.98 & 0.99 & 0.99 & 0.99 & 0.99 & 0.99 & 0.99 & 0.99 \\
-0.4 & 0.92 & 0.95 & 0.97 & 0.97 & 0.98 & 0.98 & 0.98 & 0.99 & 0.99 & 0.99 \\
-0.5 & 0.89 & 0.93 & 0.94 & 0.95 & 0.96 & 0.97 & 0.97 & 0.97 & 0.98 & 0.98 \\
\hline
\end{tabular}

TABle 3. Relative RMSFE from Monte Carlo analysis

From Table 3, one can conclude that the forecasting performance can be significantly affected by the presence of break in $d$. First, the forecast gains of taking on board the break are higher for shorter forecasting horizons regardless of the size of the break. Naturally, as the forecasting horizon increases both models tend to deliver the same forecasts and the ratio converges to one. Second, as expected, the larger the size of the break the more pronounced are the gains. For instance, for $c=0.1$ the gains are around 1 per cent for onestep ahead forecasts whereas for $c=0.5$ the gains attain 43 per cent. Third, the forecasting performance seems to be more sensitive to increases in $d$ than to decreases. Although we still find noteworthy gains in the case of a decrease in $d$, namely for larger breaks, the gains are higher when there is an increase. This is to be expected given that overdifferencing (when $\mathrm{c}<0$ ) leads to an antipersistent process which has an autocorrelation function which dies out quicker than that of a process which is underdifferenced (when $c>0$ ); see Hassler (2012) for details.

Hence, as discussed earlier, the presence of a break in the memory parameter can change the speed of transmission of the shocks to electricity prices, which can be of particular interest for policymakers and regulators, but can also change models forecasting performance and influence forecasts accuracy which can be of key importance for market participants in fields such as risk management, hedging strategies, among others. 


\section{Conclusions}

The electricity sectors around the world underwent major changes over the recent past and are still changing. In this respect, the Iberian Electricity Market constitutes a natural case study. In particular, we assess electricity price persistence in Portugal and Spain and whether it has changed with the Iberian market integration. When two electricity markets become more integrated, the price series should become less persistent.

We consider each hour of the day separately, that is, we analyze 24 time-series of day-ahead hourly prices for Portugal and another 24 series for Spain. The empirical findings are consistent with the hypothesis that market integration leads to a decrease in the persistence of the price process. In fact, the results indicate that most break dates occurred in 2009 for both Portugal and Spain, the year where we also observe a strong increase in market integration between the two countries. Furthermore, the results show that memory breaks occur earlier for night-time than day-time prices. Since electricity demand is typically lower during the night than during the day, the same physical interconnection capacity can account for a larger fraction of the total system load during the night than during the day.

Such findings support the view that the Iberian market integration process had an impact on the price dynamics of electricity prices both in Portugal and Spain. Such knowledge carries noteworthy implications for policymakers and regulators as well as market participants.

\section{References}

Alvarez-Ramirez, J. and R. Escarela-Perez (2010) Time-dependent correlations in electricity markets, Energy Economics, 32, 269-277.

Andrews, D.W.K (1993) Tests for parameter instability and structural change with unknown change point. Econometrica 61, 821-856.

Bai, J. and P. Perron (1998) Estimating and testing linear models with multiple structural changes. Econometrica 66, 47-78.

Bai, J. and P. Perron (2003) Critical values for multiple structural change tests. Econometrics journal 6, 72-78.

Breitung, J. and U. Hassler (2002) Inference on the cointegration rank in fractionally integrated processes. Journal of Econometrics 110(2), 167185.

Cecchetti, S.G., A. Flores-Lagunes and S. Krause (2006) Has monetary policy become more efficient? A cross-country analysis, Economic Journal, 116(511), 408-433.

Demetrescu, M., V. Kuzin, U. Hassler (2008) Long memory testing in the time domain. Econometric Theory 24, 176-215. 
Elliott, G. and U.K. Müller (2007). Confidence sets for the date of a single break in linear time series regressions. Journal of Econometrics, 141(2), 1196-1218.

Haldrup, N., F. S. Nielsen and M. Ø. Nielsen (2010) A vector autoregressive model for electricity prices subject to long memory and regime switching, Energy Economics, 32, no. 5, 1044-1058.

Haldrup, N. and M. Ø. Nielsen (2006) A regime switching long memory model for electricity prices, Journal of Econometrics, 135, 349-376.

Halunga, A.G., D.R. Osborn and M. Sensier (2009) Changes in the order of integration of US and UK inflation, Economics Letters 102, 30-32.

Hassler, U. (2012) Impulse responses of antipersistent processes, Economics Letters 116(3), 454-456.

Hassler, U. and B. Meller (2014) Detecting multiple breaks in long memory: The case of US inflation, Empirical Economics 46, 653-680.

Hassler, U., P.M.M. Rodrigues and A. Rubia (2009) Testing for the general fractional integration hypothesis in the time domain. Econometric Theory 25, 1793-1828.

Herrera, A.M. and E. Pesavento (2005) The decline in US output volatility: structural changes and inventory investment, Journal of Business and Economic Statistics, 23, no. 4, 462-472.

Kang, K.H., C.J. Kim and J. Morley (2009) Changes in U.S. inflation persistence, Studies in Nonlinear Dynamics \& Econometrics, 13, Article 1.

Koopman, S.J., Ooms, M., and Carnero, M.A. (2007) Periodic seasonal RegARFIMAGARCH models for daily electricity spot prices, Journal of the American Statistical Association, 102(477), 16-27.

Martins, L. and P.M.M. Rodrigues (2014) Testing for persistence change in fractionally integrated models: An application to world inflation rates, Computational Statistics \& Data Analysis, 76, 502-522.

McConnell, M.M. and G. Perez-Quiros (2000) Output fluctuations in the United States: what has changed since the early 1980s?, American Economic Review, 90, 1464-1476.

Robinson, P.M. (1994) Efficient tests of nonstationary hypotheses. Journal of the American Statistical Association 89, 1420-1437.

Schwert, G. W. (1989) Tests for unit roots: a monte carlo investigation. Journal of Business and Economic Statistics 7, 147-159.

Tanaka, K. (1999) The nonstationary fractional unit root. Econometric Theory 15, $549-582$.

Uritskaya, O. Y. and A. Serletis (2008) Quantifying multiscale inefficiency in electricity markets, Energy Economics, 30, 3109-3117.

Weron, R. (2002) Empirical Science of Financial Fluctuations, in Measuring long range dependence in electricity prices, 110-119, Springer-Verlag Tokyo. 
Weron, R. (2014) Electricity price forecasting: A review of the state-of-theart with a look into the future, International Journal of Forecasting, 30(4), 1030-1081. 


\section{WORKING PAPERS}

\section{3}

01|13 Macroeconomic forecasting using lowfrequency filters

João Valle e Azevedo | Ana Pereira

02|13 Everything you always wanted to know about sex discrimination

Ana Rute Cardoso | Paulo Guimarães | Pedro Portugal

03|13 Is there a role for domestic demand pressure on export performance?

Paulo Soares Esteves | António Rua

04|13 Ageing and fiscal sustainability in a small euro area economy

Gabriela Castro | José R. Maria | Ricardo Mourinho Félix | Cláudia Rodrigues Braz

05|13 Mind the gap! The relative wages of immigrants in the Portuguese labour market Sónia Cabral | Cláudia Duarte

06|13 Foreign direct investment and institutional reform: Evidence and an application to Portugal

Paulo Júlio | Ricardo Pinheiro-Alves | José Tavares

07|13 Monetary policy shocks: We got news! Sandra Gomes | Nikolay Iskrev | Caterina Mendicino

08|13 Competition in the Portuguese Economy: Estimated price-cost margins under imperfect labour markets

João Amador | Ana Cristina Soares

09|13 The sources of wage variation: a threeway high-dimensional fixed effects regression model

Sonia Torres | Pedro Portugal | John T. Addison | Paulo Guimarães
10|13 The output effects of (non-separable) government consumption at the zero lower bound

Valerio Ercolani | João Valle e Azevedo

11|13 Fiscal multipliers in a small euro area economy: How big can they get in crisis times?

Gabriela Castro | Ricardo M. Felix | Paulo Julio | Jose R. Maria

12|13 Survey evidence on price and wage rigidities in Portugal

Fernando Martins

13|13 Characterizing economic growth paths based on new structural change tests Nuno Sobreira | Luis C. Nunes | Paulo M. M. Rodrigues

14|13 Catastrophic job destruction Anabela Carneiro | Pedro Portugal | José Varejão

$15 \mid 13$ Output effects of a measure of tax shocks based on changes in legislation for Portugal

Manuel Coutinho Pereira | Lara Wemans

16|13 Inside PESSOA - A detailed description of the model

Vanda Almeida | Gabriela Castro | Ricardo M. Félix | Paulo Júlio | José R. Maria

17|13 Macroprudential regulation and macroeconomic activity

Sudipto Karmakar

18|13 Bank capital and lending: An analysis of commercial banks in the United States Sudipto Karmakar | Junghwan Mok 


\section{4}

1|14 Autoregressive augmentation of MIDAS regressions

Cláudia Duarte

2|14 The risk-taking channel of monetary policy - exploring all avenues

Diana Bonfim | Carla Soares

3|14 Global value chains: Surveying drivers, measures and impacts

João Amador | Sónia Cabra

4|14 Has US household deleveraging ended? a model-based estimate of equilibrium debt

Bruno Albuquerque | Ursel Baumann | Georgi Krustev

5|14 The weather effect: estimating the effect of voter turnout on electoral outcomes in italy

Alessandro Sforza

6|14 Persistence in the banking industry: fractional integration and breaks in memory Uwe Hassler | Paulo M.M. Rodrigues | Antonio Rubia

7|14 Financial integration and the great leveraging Daniel Carvalho

8|14 Euro area structural reforms in times of a global crisis

Sandra Gomes

9|14 Labour demand research: towards a better match between better theory and better data

John T. Addison | Pedro Portugal | José Varejão
10|14 Capital inflows and euro area long-term interest rates

Daniel Carvalho | Michael Fidora

11|14 Misallocation and productivity in the lead up to the Eurozone crisis

Daniel A. Dias | Carlos Robalo Marquesz | Christine Richmond

12|14 Global value chains: a view from the euro area

João Amador | Rita Cappariello | Robert Stehrer

13|14 A dynamic quantitative macroeconomic model of bank runs

Elena Mattana | Ettore Panetti

14|14 Fiscal devaluation in the euro area: a model-based analysis

S. Gomes | P. Jacquinot | M. Pisani

15|14 Exports and domestic demand pressure: a dynamic panel data model for the euro area countries

Elena Bobeica | Paulo Soares Esteves | António Rua | Karsten Staehr

16|14 Real-time nowcasting the US output gap: singular spectrum analysis at work Miguel de Carvalho | António Rua 
1|15 Unpleasant debt dynamics: can fiscal consolidations raise debt ratios?

Gabriela Castro | Ricardo M. Félix | Paulo Júlio | José R. Maria

2|15 Macroeconomic forecasting starting from survey nowcasts

João Valle e Azevedo | Inês Gonçalves

3|15 Capital regulation in a macroeconomic model with three layers of default

Laurent Clerc | Alexis Derviz | Caterina Mendicino | Stephane Moyen | Kalin Nikolov | Livio Stracca | Javier Suarez | Alexandros P. Vardoulakis

4|15 Expectation-driven cycles: time-varying effects

Antonello D'Agostino | Caterina Mendicino

5|15 Seriously strengthening the tax-benefit link

Pedro Portugal | Pedro S. Raposo

6|15 Unions and collective bargaining in the wake of the great recession

John T. Addison | Pedro Portugal | Hugo Vilares

7|15 Covariate-augmented unit root tests with mixed-frequency data

Cláudia Duarte

8|15 Financial fragmentation shocks

Gabriela Castro | José R. Maria | Paulo úlio | Ricardo M. Félix

9|15 Central bank interventions, demand for collateral, and sovereign borrowing cost Luís Fonseca | Matteo Crosignani | Miguel Faria-e-Castro
10|15 Income smoothing mechanisms after labor market transitions

Nuno Alves | Carlos Martins

11|15 Decomposing the wage losses of displaced workers: the role of the reallocation of workers into firms and job titles Anabela Carneiro | Pedro Raposo | Pedro Portugal

12|15 Sources of the union wage gap: results from high-dimensional fixed effects regression models

John T. Addison | Pedro Portugal | Hugo Vilares

13|15 Assessing european firms' exports and productivity distributions: the compnet trade module Antoine Berthou | Emmanuel Dhyne | Matteo Bugamelli | Ana-Maria Cazacu | Calin-Vlad Demian | Peter Harasztosi | Tibor Lalinsky | Jaanika Meriküll | Filippo Oropallo | Ana Cristina Soares

14|15 A new regression-based tail index estimator: an application to exchange rates

João Nicolau | Paulo M. M. Rodrigues

15|15 The effect of bank shocks on firm-level and aggregate investment João Amador | Arne J. Nagengast

16|15 Networks of value added trade João Amador | Sónia Cabral

17|15 House prices: bubbles, exuberance or something else? Evidence from euro area countries Rita Fradique Lourenço | Paulo M. M. Rodrigues 


\section{6}

1|16 A mixed frequency approach to forecast private consumption with ATM/POS data

Cláudia Duarte | Paulo M. M. Rodrigues | António Rua

2|16 Monetary developments and expansionary fiscal consolidations: evidence from the EMU

António Afonso | Luís Martins

3|16 Output and unemployment, Portugal, 2008-2012

José R. Maria

4|16 Productivity and organization in portuguese firms

Lorenzo Caliendo | Luca David Opromolla | Giordano Mion | Esteban Rossi-Hansberg

5|16 Residual-augmented IVX predictive regression

Matei Demetrescu | Paulo M. M. Rodrigues

6|16 Understanding the public sector pay gap Maria M. Campos | Evangelia Papapetrou | Domenico Depalo Javier J. Pérez | Roberto Ramos

7|16 Sorry, we're closed: loan conditions when bank branches close and firms transfer to another bank

Diana Bonfim | Gil Nogueira | Steven Ongena

8|16 The effect of quantitative easing on lending conditions

Laura Blattner | Luísa Farinha | Gil Nogueira
9|16 Market integration and the persistence of electricity prices João Pedro Pereira | Vasco Pesquita | Paulo M. M. Rodrigues | António Rua 



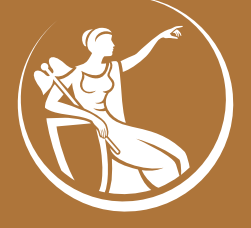

